\title{
ENTRE GRAMÁTICAS: EMPRÉSTIMOS LINGUÍSTICOS E APRENDIZAGEM DE LÍNGUAS
}

\author{
Gean Damulakis ${ }^{1}$ e Andrew Nevins ${ }^{2}$
}

Neste volume, elegemos dois temas bastante instigantes, mas que ainda carecem de estudos mais sistemáticos no Brasil: empréstimos linguísticos e ensino/aprendizagem de L2 e L3. O que une esses dois temas são o contato entre gramáticas distintas e os fenômenos que dele decorrem, levando em conta o uso de elementos linguísticos de uma língua por falante nativo de outra. Tanto a aquisição de L2 e L3 quanto os empréstimos linguísticos, ao evidenciar relações estabelecidas entre gramáticas, podem apontar para a natureza da Gramática Universal (GU) e também de fatores cognitivos universais (perceptuais, por exemplo), bem como para questões de natureza extralinguística (como grau de prestígio da língua fonte e da língua alvo, ou da L2/L3 e da L1/L2, respectivamente).

Além disso, vários são os aspectos teóricos que podem ser desenvolvidos e várias questões podem ser respondidas a partir da investigação dos fenômenos relacionados à adoção e à adaptação de empréstimos e da constituição da interlíngua (recurso linguístico utilizado por aprendizes de L2, L3, muitas vezes com características independentes das línguas envolvidas). Entre as questões teóricas ainda controversas na fonologia de empréstimos está a relevância da percepção na formação da representação lexical: os itens adaptados sofreriam a ação de um filtro perceptual para a formação do input a receber ajustes fonológicos (Silverman, 1992) ou eles seriam representados no léxico com a mesma configuração segmental da língua fonte (Jacobs \& Gussenhoven, 2000)? Silverman (1992) postula a existência de dois níveis para a adaptação de empréstimos: um nível perceptual e um operativo. No primeiro, estaria um filtro forjado pela gramática nativa, que indicaria quais

1 Professor Doutor da Universidade Federal do Rio de Janeiro. E-mail: damulakis@letras.ufrj.br

2 Professor Doutor da Universidade Federal do Rio de Janeiro. E-mail: andrewnevins@letras.ufrj.br 
são os segmentos correspondentes, no inventário fonológico nativo, ao "sinal acústico superficial" (sem representação fonológica) do item a ser adaptado. No segundo, estariam as regras de ajustes de caráter fonotático na língua nativa. Já Jacobs \& Gussenhoven (2000) defendem que o que serve de input seria "representação fonológica completamente especificada", idêntica ao input de uma criança adquirindo língua. Dessa forma, o nível perceptual seria abandonado; o que forja a adaptação seria a satisfação de restrições, altas na hierarquia da língua nativa. Formulando de outro modo: haveria a incapacidade de discriminar características fonológicas presentes em línguas não-nativas e ausentes na nativa? Ou seria uma questão apenas da produção, restringida pela gramática nativa? Outro ponto importante seria saber se o grau de bilinguismo consegue afetar essa inabilidade de discriminação (e/ou produção) e, consequentemente, a representação das estruturas linguísticas na L1. Da mesma forma, é importante considerar a influência da mídia a partir da qual os itens foram emprestados, se através da fala ou da escrita. Na primeira situação, as pistas para a adaptação tendem a ser acústicas; na segunda, as pistas são ortográficas.

Em relação aos empréstimos no $\mathrm{PB}$, um caso digno de nota seriam as adaptações de vogais não existentes no sistema vocálico dessa língua. Sabemos que línguas tendem a adaptar segmentos de acordo com o seu sistema. Por exemplo, no PB, sistema no qual não há distinção entre longas e breves, palavras como 'loop' [u:] e 'look' [ซ] serão adaptados pela mesma vogal [u], mesmo a primeira sendo longa e a segunda breve (ou tense/lax) no inglês: 'o avião deu um 1[u]p[I]' e 'ela/ele mudou de $1[\mathrm{u}] \mathrm{k}[\mathrm{I}]$ '. A seguir, indicamos outros exemplos de adaptações vocálicas em empréstimos.

\section{Adaptações de vogais do francês e do alemão}

Podemos dizer que há determinadas características não contrastivas na língua receptora que não são percebidas e/ou reproduzidas. O caso também se dá quando o sistema vocálico não é capaz de interpretar a co-ocorrência de alguns traços. No PB, se uma vogal é [+alto, +arredondado], ela será previsivelmente [+recuado]; analogamente, se ela for [+alto, -recuado], será previsivelmente [-arredondado]. Por conta disso, uma vogal percebida como contendo o primeiro par de traços, será adaptada por [u] e com o segundo par de traços, [i]. Isso justifica a flutuação em alguns itens lexicais no $\mathrm{PB}$, como $\mathrm{p}[\mathrm{u}] \mathrm{rê}$ e $\mathrm{p}[\mathrm{i}] \mathrm{rê}$ ou $\mathrm{b}[\mathrm{u}]$ fê e $\mathrm{b}[\mathrm{i}]$ fê, para a adaptação do [y] do francês, vogal que tem, conjuntamente [+alto], [-recuado] e [+arredondado]. Essa oscilação, entretanto, parece ser fonte de origem diversa: as adaptações com [i] devem ter surgido através da fala e as com [u], através da escrita. Isso pode ser reforçado pela adaptação dessas vogais com origem no alemão, como vemos a seguir. 
Segundo Peperkamp (2004), há dois tipos de empréstimos lexicais: os integrados (aqueles que entraram no léxico da língua alvo e dos quais muitos falantes não recuperam o status de 'empréstimos') e os empréstimos lexicais com adaptação online (os que são emprestados 'aqui e agora'). Várias palavras do alemão, muito marcadamente sobrenomes, são adaptadas para o sistema vocálico do PB. Por exemplo, Sch[y]rmann, K[y]rten, $B[\mathrm{y}]$ ndchen, $M[\mathrm{y}] l l e r$, todas pronunciadas em PB, quase invariavelmente, com a alta anterior não-arredondada [i], como em (Família) ‘Sch[i]rmann', (Gustavo) 'K[i]rten', (Gisele) ‘B[i]ndchen', (Otávio) 'M[i]ller’’ , ou seja, com a perda do arredondamento nessas vogais. O mesmo traço é abandonado em palavras como Schr[ø]der, pronunciados como Schr[e]der ${ }^{4}$, nome de município em Santa Catarina, ou mesmo G[e]the para G[ø]the, o grande escritor alemão.

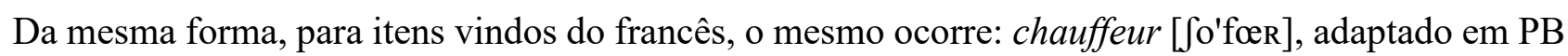
como [ [o'fex]. Assim, vemos que a altura e a anterioridade dos segmentos vocálicos são mantidas, e o arredondamento, descartado:

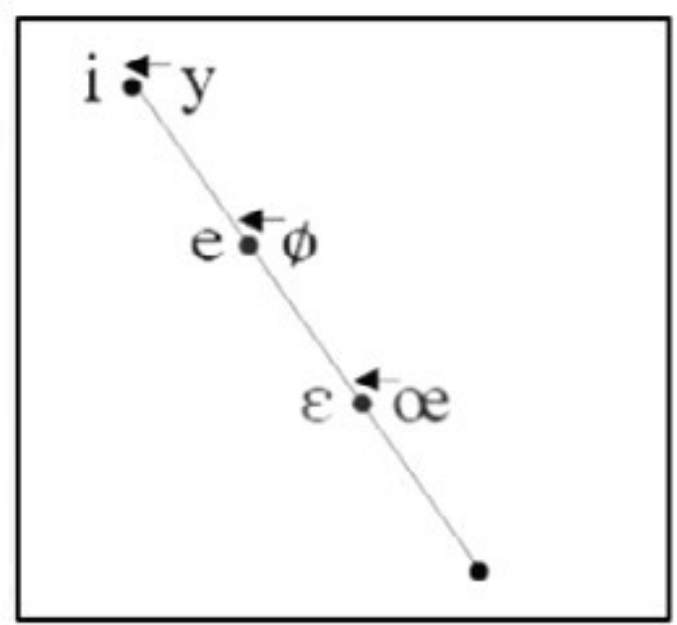

Figura 1 - Adaptação de vogais anteriores arredondadas no PB

Uma questão a ser resolvida é por que o traço sobrevivente é [-recuado] no lugar de [+arredondado]. Em outras línguas, como o inglês, por exemplo, o traço abandonado pode ser [-recuado]. O padrão do PB é bastante consistente com a adaptação da mesma vogal em empréstimos do francês no crioulo mauritano (CM), como demonstra por Jacobs \& Gussenhoven (2000; 203) em uma análise otimalista. Segundo a análise proposta, o traço [+arredondado] seria marcado para as vogais anteriores, o que favorece a adaptação com as vogais anteriores não arredondadas. A restrição que proíbe a co-ocorrência da associação dos traços [Labial] e [Coronal] ao Ponto de Vogal estaria

3 Uma outra maneira de adaptar vogais anteriores arredondadas no PB é desmembrar a vogal em duas raízes: $/ y / \rightarrow$ iw], como em Führer $\rightarrow$ F[iw]rer ou em über $\rightarrow$ [iw]ber, de Übermensch e Übermodel.

4 Em todos esses casos, a ortografia aponta para a vogal posterior: Schürmann, Kuerten, Bündchen, Schroeder, Goethe. 
alta na hierarquia do CM, o que impede que vogais anteriores arredondadas apareça na superfície do $\mathrm{CM}$, mesmo que figurem no input.

Aparentemente essa proposta poderia ser seguida com os dados do $\mathrm{PB}$, uma vez que o sistema vocálico dessa língua e o do CM exibem certa similaridade ${ }^{5}$. Entretanto, os dados do PB não são tão bem-comportados. Como dissemos acima, ainda para a vogal [y], por exemplo, temos itens do francês simetricamente opostos em relação à adaptação: $\mathrm{p}[\mathrm{y}] \mathrm{rée}, \mathrm{b}[\mathrm{y}] \mathrm{ffet} \mathrm{e}$ men[y] $]^{6}$, adaptados no PB com [u] (purê, bufê, menu) co-ocorrem com formas com [i] (pirê, bifê, meni). Considerando que os empréstimos online com essas vogais, que demandam uma adaptação instantânea, favorecem a perda do arredondamento (como vistos nos dados provenientes do alemão), consideramos que as adaptações com $[u]$ se devem à influência da ortografia. Ainda em relação à via de entrada no léxico, se pela fala ou pela escrita, e suas repercussões distintas nas adaptações, Araújo \& Agostinho (2009: p. 322) nos fornecem o exemplo do par 'tricô' e 'fricote', ambos vindos do francês com adaptações distintas no que se refere à consoante flutuante /t/. Segundo os autores, 'tricô' (tricot), adaptado sem a consoante, teria entrado pela fala, ao passo que 'fricote' (fricot), com a manutenção da consoante e com reparo da epêntese da vogal, teria entrado pela escrita.

\section{Adaptações de vogais do inglês}

Em PB, os empréstimos do inglês com a vogal anterior baixa não arredondada [æ] costumam oscilar entre $[\mathrm{a}]$ e $[\varepsilon]$. Os super-heróis podem ser $\mathrm{B}[\mathrm{a}] \mathrm{tm}[\mathrm{a}] \mathrm{n}$ ou $\mathrm{Fl}[\varepsilon] \mathrm{sh}$, embora venham da mesma vogal do inglês ([æ]). A maior parte, entretanto, passa a $[\varepsilon]: \mathrm{j}[\varepsilon] \mathrm{zz}, \operatorname{tr}[\varepsilon] \mathrm{sh}, \mathrm{c}[\varepsilon] \mathrm{sh}^{7}, \operatorname{Superm}[\varepsilon] \mathrm{n}$ etc. Defendemos que, em princípio, as adaptações com [a] sejam influenciadas pela ortografia; por outro lado, as adaptações com $[\varepsilon]$ são influenciadas por pistas acústicas. A vogal [æ] do inglês possui o seguinte conjunto de traços [+baixo, -rec, -arred, (-ATR)], o que não encontra interpretabilidade em PB. Sendo assim, há duas possibilidades: ou se mantém o subconjunto [+baixo, -arred, -ATR], logo /a/; ou se mantém o subconjunto [-rec, -arred, -ATR], $\operatorname{logo} / \varepsilon /$. A preferência mais robusta, no entanto, é por $[\varepsilon]$. Casos mais raros como o de $B / \mathrm{a} / \mathrm{tm} / \mathrm{a} / n$ podem ser explicados, muito provavelmente, pela

5 O sistema vocálico do CM apresenta 5 vogais: [a, e, i, o u], equivalente ao sistema reduzido do PB nas pretônicas, por exemplo. Entretanto, a maior similaridade à que nos referimos aqui, mais particularmente relevante a esse tipo de adaptação, é referente à inexistência de anteriores arredondadas (e de posteriores não-arredondadas).

6 O caso de menu pode sofrer adaptações especializadas para alguns falantes: men[i] para cardápio e men[u] para 'série de opções' (no computador, por exemplo).

7 Para um tratamento da assimetria da inserção da vogal em contexto de fricativas coronais, pela Teoria da Otimalidade, veja-se Damulakis, 2017. 
influência da escrita. De todo modo, a análise por traços parece ser menos efetiva que aquela referente a pistas acústicas e ortográficas. Consideramos, portanto, que a preferência por $[\varepsilon]$ se deva ao F2 dessa vogal, muito mais próximo de $[\varepsilon]$ que de [a] (esta última muito mais alicerçada por pistas ortográficas).

No caso da adaptação de $[\Lambda]$ do inglês, observamos uma flutuação um pouco maior no PB:

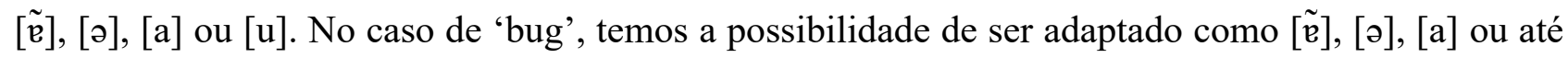
mesmo $[\mathrm{u}]$, dependendo de questões fonológicas (como tonicidade) e morfológicas (como categoria lexical ou status flexional). O caso mais interessante nesse caso é que o sistema vocálico do português apenas contém [ə] como alofone de [a], não permitindo essa vogal do tipo schwa em posição tônica, exceção feita a alguns dialetos, apenas em palavras em que a vogal [a] se encontra entes de consoante nasal. Vejamos abaixo uma pequena lista de palavras com essa vogal:

(1)

a) blush, bug (e derivados: bugar, bugado), cluster, crush (e derivados: crushar, descrushar), h $u$ b, kitesurf, cup ( cake), muffin, nugget, r $u$ sh, sh $u$ ffle, truck (food $\sim$ ), trust (mas ketch $u$ p [u])

b) Duster (carro), Scruff (aplicativo), Starbucks, Subway, Speak Up (revista), Up (Fiat)

c) backup, upload ['upar'], Pickup (picape), setup, startup, pop-up

d) lunch, brunch, dumping

Os dados acima foram subdivididos da forma a seguir. Em (1a), temos a maior parte dos dados

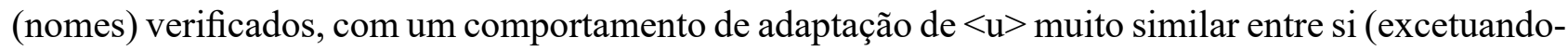
se, nesse caso, os derivados), normalmente com [ə]. Em (1b), encontramos nomes de marcas, cujos itens exibem um comportamento de adaptação da vogal associável a (1a). Em (1c), encontramos dados com o formativo up, adaptado, normalmente com [a]: esse composto pode ser considerado lexicalizado com essa vogal. Já (1d) apresenta itens com $<\mathrm{u}>$ seguido de nasal (normalmente adaptada com $[\tilde{\mathfrak{e}}]$ ), como a adaptação ortográfica 'lanche' (e derivados).

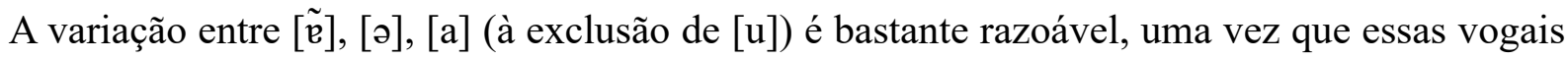
são muito próximas entre si, foneticamente, pois são todas vogais centrais. No PB, especificamente, 
podemos dizer que as três são variantes posicionais da vogal $/ \mathrm{a} /{ }^{8}$. O problema surge quando há associação com o [u]. Vejamos as sentenças:

(2)

Deu um b[ə]g no jogo.

$\mathrm{B}[\mathrm{u}]$ guei com o que ela falou.

Fiquei b[u]gado com essa afirmação.

A adaptação de nomes parece favorecer a adoção da vogal central. Dessa forma, as pistas para essa adaptação devem ser de ordem acústica. Já os itens adaptados como verbos (ou uso adjetival do particípio) parece favorecer o uso de [u], o que exemplifica o fenômeno tratado por Jurgec (2014) como 'Efeito Oprah' no holandês. No caso do PB, essa oscilação está muito recente no léxico. É possível imaginar uma situação em que derivados sejam tão usados, de forma passar a influenciar a vogal do nome (como o caso de 'surf', como veremos adiante), devido à necessidade de associação lexical. Ainda sobre as correlações entre os empréstimos e as derivações e sobre o 'Efeito Oprah', falaremos a seguir, na seção 4 .

\section{A influência da ortografia (da L1 e da L2)}

Como dito acima, os itens com [y] advindos do francês foram adaptados ora com [u] ora [i]. Defendemos que a adaptação com [u] ocorra por influência da escrita. Sobre a influência da escrita em adaptações de empréstimos, Hamann \& Colombo (2017) propõem tratamento formal de como a gramática de leitura (Reading Grammar, doravante RG) influencia a realização fonética de itens emprestados, atribuindo a esses um mapeamento grafema-fonema bastante similar ao mapeamento executado na L1. Esse modelo complementa, com restrições ortográficas (do tipo ORTH), o modelo proposto por Boersma \& Hamann (2009), que propuseram o BiPhon, no qual restrições de cunho perceptual interagem com restrições estruturais. Como as autoras afirmam, o mapeamento na RG é operante entre línguas que apresentem escrita alfabética e de mesmo alfabeto. Ainda segundo as autoras, uma vez adquirida a escrita da L1, será esse a gramática de leitura utilizada para a L2.

8 O som [ə], por exemplo, também pode ser ouvido no PB em hesitações e nas reproduções metalinguísticas de

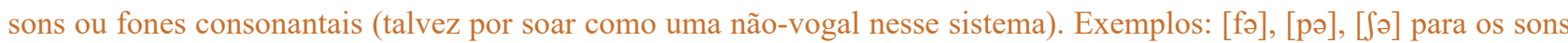
[f], [p], [S], respectivamente. 
Ainda segundo Hamann \& Colombo (2017), as vogais tendem a ser mapeadas por restrições acústicas, ao passo que as consoantes por pistas ortográficas. O exemplo tratado pelas autoras é da adaptação de itens do inglês no italiano, segundo as quais, mesmo que não haja nenhuma pista acústica, uma vez que o inglês não dispõe de consoantes geminadas, palavras em inglês grafadas com consoantes duplas são adaptadas com esse tipo de segmento no italiano, devido ao fato de ser a duplicação de consoantes o recurso ortográfico usado nesta língua para as geminadas. As autoras assumem a interação entre restrições ortográficas e acústicas, atuantes no italiano, nos seguintes formatos, respectivamente:

(3)

a) $<\beta i \beta i>/ C: /$ : Assinale uma marca de violação se um grafema de duas letras idênticas não for mapeado em geminada na superfície, e vice-versa.

b) $[\mathrm{midF} 2] / \mathrm{a} / \mathrm{:}$ Assinale marca de violação a toda forma auditiva com valores médios de F2 que não seja mapeada na vogal /a/ na superfície.

Pelo fato de a restrição ortográfica $<\beta \mathrm{i} \beta \mathrm{i}>/ \mathrm{C}: /$, do $\mathrm{RG}$ do italiano, exercer uma forte atuação nessa língua e as restrições acústicas $[\mathrm{midF} 2] / \mathrm{a} /$ e $[\mathrm{highF2}] / \varepsilon /$ dominarem as restrições da $\mathrm{RG}$ do italiano $<\mathrm{u}>/ \mathrm{u} / \mathrm{e}<\mathrm{a}>/ \mathrm{a} /$ (que exigem mapeamento de $<\mathrm{u}>\mathrm{em} / \mathrm{u} /$ e de $<\mathrm{a}>\mathrm{em} / \mathrm{a} /$ ), respectivamente, uma palavra como buffer pode emergir como ['baf.fer] e rally como ['rel.li].

No caso do PB, defendemos a existência de interações de restrições ortográficas da L1 e restrições acústicas. Assim:

(4)

a) $[\mathrm{midF} 1] / \mathrm{VM} / \mathrm{s} \quad$ Assinale marca de violação a toda forma auditiva com valores médios de primeiro formante que não seja mapeado na superfície como vogal média.

b) [mid F2] /A/: $\quad$ Assinale marca de violação a toda forma auditiva com valores médios de segundo formante que não seja mapeado na superfície como vogal central. 
c) $<\mathrm{u}>/ \mathrm{u} / \mathrm{i} \quad \quad$ Assinale uma marca de violação a todo grafema $<$ u $>$ que não seja mapeado por $/ \mathrm{u} /$.

A atuação conjunta das restrições acústicas [midF1]/VM/ e [mid F2] /A/, acima de $<\mathrm{u}>/ \mathrm{u} /$ (da RG do PB), faz com que os exemplos de (1a) e (1b) sejam adaptados com [ə]. Nesse caso, apenas as derivações estariam sujeitas à restrição $<\mathrm{u}>/ \mathrm{u} /$. Isso se deve ao 'Efeito Oprah' (JURGEC, 2014), como veremos a seguir.

\section{Das formas derivadas}

Outra questão relevante a ser considerada é a derivação (sobretudo a verbalização). Verbos são categorias muito mais difíceis de sofrerem empréstimos (HASPELMATH \& TADMOR, 2009). No caso de verbalizações no PB a partir de empréstimos, a tendência maior é que as vogais sejam nativizadas, mesmo que convivendo em paralelo com o nome contenham a uma adaptação diferente. É o caso de crush [ə] (mas 'crushar', 'descrushar', com [u]) e surf ([u] [ə]), mas surfar [u], *s[ə]rfar.

Casos de assimetria entre os empréstimos e suas derivações são recorrentes em empréstimos em outras línguas. Jurgec (2014) descreve o que chama de ‘Efeito Oprah' (Oprah Effect), através do qual palavras derivadas de um empréstimo costumam se aproximar mais dos padrões nativos que o termo originalmente emprestado. Os dados do holandês exibidos em Jurgec (2014) são mostrados abaixo. Nos exemplos, vemos que a aproximante [I] ocorre em empréstimos, mas nos derivados aparecem o equivalente nativo $[\mathrm{R}]$.

(5) Reprodução de JURGEC (2014: p.1)

\section{Dutch affixation: $1 \rightarrow \mathrm{R}$}

BARE ROOT I

Op[I]ah

$\mathrm{Ba}[\mathrm{I}] \mathrm{ack}$

[I]eading

Flo[ı]ida
'Oprah'

'Barack'

'Reading'

'Florida'
AFFIXED $\mathrm{R}$

Op[r]ah-tje

$\mathrm{Ba}[\mathrm{r}] \mathrm{ack}-\mathrm{se}$

[R]eading-je

Flo[R]ida-tje
*Op[r]ah-tje

*Ba[r]ack-se

${ }^{*}$ [I] eading-je

*Flo[r]ida-tje
'DIM'

'ADJ'

'DIM'

'DIM'

Importante questão é qual seria o substituto do elemento que aparece nos derivados. Seria ele mais suscetível a restrições ortográficas ou a restrições acústicas? Os exemplos trazidos por Jurgec (2014) não conseguem responder satisfatoriamente a essa pergunta, uma vez que o grafema $<\mathrm{r}>$ 
veicula um fonema na língua fonte muito próximo fonema que o mesmo grafema veicula na língua alvo. Se mantivéssemos a mesma relação, era de se esperar que surgisse o fonema /a/, mais próximo de [ə]. Entretanto, no caso em pauta, o que emerge é o /u/. Ou seja: a atuação da restrição ortográfica da $\mathrm{L} 1<\mathrm{u}>/ \mathrm{u} /$ é o que parece prevalecer. Vejamos:

\section{(6)}

Raiz Derivado (Recategorizado)

$\mathrm{b}[ə] \mathrm{g} \quad \mathrm{b}[\mathrm{u}] \mathrm{gar}, \mathrm{b}[\mathrm{u}]$ gado, ${ }^{*} \mathrm{~b}[$ [ə]gar, *b[ə]gado, *b[a]gar, *b[a]gado

$\operatorname{cr}[ə] \mathrm{sh} \quad \operatorname{cr}[\mathrm{u}] \operatorname{shar}, \operatorname{descr}[\mathrm{u}] \operatorname{shar}^{9},{ }^{*} \operatorname{cr}[ə] \operatorname{shar},{ }^{*} \operatorname{descr}[ə] \operatorname{shar}, * \operatorname{cr}[\mathrm{a}] \operatorname{shar},{ }^{*} \operatorname{descr}[\mathrm{a}] \operatorname{shar}$

$\mathrm{s}\left[\right.$ ə]rf $\sim \mathrm{s}[\mathrm{u}] \mathrm{rf} \quad \mathrm{s}[\mathrm{u}] \mathrm{rfar}, \mathrm{s}[\mathrm{u}] \mathrm{rfista},{ }^{*} \mathrm{~s}[\partial] \mathrm{rfar},{ }^{*} \mathrm{~s}[\partial] \mathrm{rfista},{ }^{*} \mathrm{~s}[\mathrm{a}] \mathrm{rfar}, *_{\mathrm{s}}[\mathrm{a}] \mathrm{rfista}$

Ponto importante de interface com restrições fonológicas, nesse caso, é o fato de que essas derivações 'escondem' a vogal alvo em uma posição menos proeminente, em termos de acento. Notem que é essa interação que permite que a prefixação não promova a mesma alternância na base vista com processos que envolvem adição de sufixos. Vejamos:

(7)

Raiz Derivado

trust (lei) anti-tr[ə]st, (lei) *anti-tr[u]st $(\leftarrow \operatorname{tr}[ə] \mathrm{st})$

rush (horário) pré-r[ə]s sh, (horário) *pré-r[u]sh $(\leftarrow \mathrm{r}[ə] \mathrm{sh})$

A manutenção dessa alternância de vogais cria um problema de associação de itens lexicais, comuns em casos de derivação e recategorização, de forma que é possível pensar na pressão de derivados sobre os nomes originalmente emprestados. Esse seria o caso de surf, que, a partir dos derivados ('surfista', 'surfar') tenha sofrido a padronização para surf, também com $/ \mathrm{u} /{ }^{10}$. Por esse

9 Note-se que aqui temos também uma alternância do rótico muito próxima daquela que ocorre no holandês: c[..ə] $] \mathrm{sh} \rightarrow(\mathrm{des}) \mathrm{c}[\mathrm{ru}] \mathrm{shar}$.

10 A adaptação ortográfica reforça essa ideia: 'surfe'. Note-se, no entanto, o uso de kitesurf, que não apresenta, 
motivo, podemos pensar em um momento em que surf tenha sido adaptado com [ə], em seguida tenha passado a ser pronunciado com $[\mathrm{u}]$ por pressão dos derivados.

\section{Influência da ortografia da L2}

Casos que parecem não ter sido abarcados pela análise acima são apresentados por itens como (biscoito) waffle, lojas duty(-free) e (música) country, que são adaptados, respectivamente, por $w$ [ej]ffle, lojas $d[ə] t y(-f r e e)$ e (música) $c[$ av]ntry. Esses itens não podem ser justificados por pistas acústicas - uma vez que as vogais do inglês são [æ], [u] e [ $\Lambda$, respectivamente - , nem por restrições ortográficas da L1 - que levariam às adaptações com [a], [u] e [ov]. Defendemos que esses casos sejam uma aplicação de restrições ortográficas da língua fonte, ou seja, do inglês. Assim, haveria uma sobregeneralização das regras ortográficas dessa língua $<\mathrm{a}>/ \mathrm{ej} /,<\mathrm{u}>/ \mathrm{\partial} / \mathrm{e}<\mathrm{ou}>/ \mathrm{a} \mho /$.

Os casos exemplificados aqui podem ser vistos como decorrentes da existência de cofonologias, no sentido de que algumas raízes são levadas a comportamentos fonológicos distintos, a depender de status derivacional, e de co-ortografias, no sentido de que relações grafo-fonêmicas do inglês são levadas em consideração para algumas palavras. De forma esquemática, podemos pensar nos seguintes mapeamentos:

(8) Interações entre restrições ortográficas e restrições acústicas (para /æ/)

\begin{tabular}{|l|l|l|}
\hline $\begin{array}{l}\text { Tipo de adaptação para } \\
/ æ /\end{array}$ & Exemplos & Causa \\
\hline$<\mathrm{a}>\rightarrow[\mathrm{a}]$ & Batman 'personagem' & $\begin{array}{l}\text { Restrição ortográfica da L1: } \\
<\mathrm{a}>/ \mathrm{a} /\end{array}$ \\
\hline$/ æ / \rightarrow[\varepsilon]$ & Flash: 'personagem' & Restrição acústica \\
\hline$<\mathrm{a}>\rightarrow[$ ej] & Waffle 'tipo de biscoito' & $\begin{array}{l}\text { Restrição ortográfica da L2: } \\
<\mathrm{a}>/ \text { jej/ }\end{array}$ \\
\hline
\end{tabular}

(9) Interações entre restrições ortográficas e restrições acústicas (para $/ \Lambda /$ )

\begin{tabular}{|l|l|l|}
\hline Tipo de adaptação para $/ \Lambda /$ & & Causa \\
\hline$<\mathrm{u}>\rightarrow \mathrm{u}]$ & bugar, surfar & 'Efeito Oprah' (JURGEC, 2014) \\
\hline$/ \Lambda \rightarrow[ə]$ & bug, rush, crush & $\begin{array}{l}\text { Restrição acústica: [midF1]/VM/ e } \\
\text { [mid F2] /A/. }\end{array}$ \\
\hline
\end{tabular}

nesse momento da língua, ocorrência de derivação e recategorização. A derivação para 'kites[u]rfar' ou 'kites[u]rfista' poderia dar azo à pronúncia kites[u]rf. 


\section{Os artigos deste volume}

Começamos o número com uma entrevista com Ellen Broselow, linguista da Stony Brook University (Nova Iorque), cujo trabalho investiga a fonologia de empréstimos, aquisição e a relação desses com a percepção. Seu trabalho procura unir métodos experimentais e modelos teóricos na investigação sobre esses temas. Entre as questões abordadas na entrevista estão a importância da percepção para esses fenômenos, GU e universais linguísticos, assim como comparação sobre modelos baseados em regras e aqueles baseados em restrições. Como bem lembra a pesquisadora, há um corrente debate acerca do papel da percepção sobre a adaptação de empréstimos: falantes nãonativos percebem padrões inexistentes na sua língua, mas não os produzem ou eles simplesmente não discriminam esses padrões e, por isso, não os realizam? É provável que nenhum desses polos consiga analisar satisfatoriamente todas as situações envolvendo tais adaptações, o que demanda a consideração de fatores extralinguísticos. Além disso, é necessário considerar que fatores perceptuais universais devem interferir nesses casos.

\section{O squib Sobre inter-relações de gramáticas durante os estágios iniciais de aquisição} fonológica de L3, de Brenda da Silva Barreto (doutoranda/UFRJ), intitulado, traz algumas reflexões acerca das interferências (e da possibilidade de previsibilidade dessas interferências) que podem ocorrer entre as três línguas envolvidas nesse processo. Muitas são as pesquisas que lidam com as interferências da língua materna na L2 e com as hipóteses de acesso à GU durante esse processo. O campo de trabalho com a L3 (e Ln) tem mostrado que há especificidades nessa aprendizagem, sobretudo devido ao fato de que, na L3 (em diante), o número de possíveis gramáticas candidatas a fornecer padrões é maior que em um processo de aquisição (ou aprendizagem) de uma L2. A autora também nos traz a hipótese de a L3 ser uma fonte de interferência na L2, diferentemente do que ocorre com a L1, o que pode ser uma dica importante sobre o acesso à GU após o período crítico. Para isso, também reflete para a relevância da proximidade ou distanciamento tipológico entre as línguas envolvidas.

Os casos de empréstimos também nos fornecem indicação de contatos entre povos falantes de línguas distintas, embora não necessariamente atestados por fontes ou documentos escritos, por exemplo. Não é à toa que dados reputados como empréstimos devem ser cuidadosamente retirados da base de análise para se chegar ao parentesco entre línguas. Tangenciando esse aspecto, o artigo 
Tupi-Guarani loanwords in Southern Arawak: taking contact seriously, de autoria de Fernando Orphão de Carvalho (Unifap), fornece uma análise que desfaz crenças sobre a existência de alguns empréstimos de línguas Tupi-Guarani em línguas Arawak. O trabalho faz uma análise bem acurada de itens, tomados como empréstimos por outros autores, mostrando que há justificativas plausíveis para considerá-los como desdobramentos lexicais internos a línguas da família Arawak; para tanto, o autor se utiliza de argumentos embasados em aspectos fonológicos e morfológicos de línguas dessa família. O autor também fornece uma lista de itens de empréstimos do Guarani (Família Tupi-Guarani) na língua Terena (família Arawak).

Itens emprestados podem também oferecer casos de insubordinação a padrões linguísticos internos, tanto na fonologia quanto na morfossintaxe. Em relação a este último subnível linguístico, o artigo Uma nota sobre medir e contar com palavras emprestadas do português no kadiwéu (família Guaikurú, falada no Mato Grosso do Sul), de autoria de Filomena Sandalo (UNICAMP), mostra exemplos de empréstimos de numerais do português no Kadiwéu, os quais se comportam diferentemente dos numerais nativos nessa língua. O Kadiwéu é uma língua classificadora, e os numerais dessa língua (até 'três') exigem classificadores. Entretanto, os numerais emprestados do português (quatro em diante) podem dispensar esse elemento. Dessa maneira, a autora defende que esse fenômeno aponta para a coexistência de duas gramáticas: uma que exige classificadores para numerais nativos e outra que os dispensa diante de elementos lexicais análogos emprestados do PB.

O artigo 'Noruega', Ndo ro hwêkê, Peido na cara, do pesquisador Rafael Nonato Bezerra (Museu do Índio do Rio de Janeiro), traz alguns exemplos de um tipo de ampliação lexical motivada por contato linguístico, ainda pouco descrito e analisado: o pareamento fonológico, que se dá através seleção de itens ou de potenciais expressões pré-existentes e seu consequente reinvestimento de significado devido à similaridade fonética dessas formas com o item da língua alvo. No caso da língua analisada, o Kĩsêdjê (língua da família Jê, falada no Parque Indígena do Xingu), esse processo costuma ser motivado particularmente pela geração de humor que a expressão cria na língua. O autor indica e analisa exemplos desse processo, que, ao invés de exibir a adaptação fonológica, através da substituição de segmentos e padrões do português pelos do Kĩsêdjê, exibe a busca por similaridade fonética com palavras e sintagmas da língua alvo, com o propósito de criar expressões nonsense ou jocosas, como no caso exemplificado no próprio título do artigo.

O mesmo tipo de investigação sobre a transposição entre dois sistemas de morfofonologia completamente diferentes (e os resultados jocosos) se encontra no trabalho de Paulo Jeferson Pilar 
Araújo e Thaisy Bentes, intitulado Jogos de sinais híbridos e empréstimos do português na língua brasileira de Sinais - Libras. Os autores focalizam o uso de trocadilhos em línguas de sinais, nos quais os falantes de Libras pegam emprestados aspectos da língua falada, no caso o PB, apropriandose de elementos não-nativos para efetuar uma brincadeira.

O português do Brasil (PB), além de ter contato com as línguas indígenas (as chamadas autóctones), também tem contato com as línguas de imigração (também conhecidas como línguas alóctones). Esse contato também produz situações de adoções de empréstimos de ambas as partes, como não poderia deixar de ser. O artigo A contribuição do português para a constituição lexical do Hunsrückisch em situação de contato linguístico, de Karen Pupp Spinassé (UFRGS), analisa alguns padrões lexicais do Hunsrückisch (língua germânica, falada predominantemente no Sul do país) e mostra alguns casos de empréstimos que essa língua recebeu do PB. A autora ressalta, entretanto, que, apesar de emprestados do $\mathrm{PB}$, esses elementos lexicais costumam se conformar à morfossintaxe do Hunsrückisch.

Por conta de questões referentes à história da constituição do país, o português do Brasil apresenta contribuições lexicais das línguas mais diversas. Um desses exemplos é o japonês, que oferece uma gama de contribuições ao léxico do português, muitos de adoção bem recente na história do PB. O artigo Adaptação de empréstimos de origem japonesa no português: uma análise preliminar, de autoria de Lara Bertazzo Richter (UFSC/CNPq) e Ana Lívia Agostinho (UFSC), analisa como empréstimos do japonês são adaptados no português do Brasil, considerando as diferenças fonológicas entre essas duas línguas, sobretudo as concernentes aos padrões acentuais e silábicos.

Como vimos acima, os trabalhos recobrem um espectro amplo de abordagens teóricas e línguas diversas, tanto do ponto de vista tipológico quanto do parentesco. Com esses trabalhos, e com sua multiplicidade de temas, esperamos que o interesse sobre esses assuntos seja intensificado. A investigação sobre esses fenômenos pode ser relevante por desvendar diversos aspectos sobre a natureza da linguagem e de sua interação com outros fatores cognitivos e sociais. 


\section{REFERÊNCIAS}

ARAÚJO, Gabriel de; AGOSTINHO, Ana L. Nativização e manutenção do acento paroxítono em Português. Signótica. Goiânia, v. 21, n. 2, p. 305-340, jul/dez. 2009.

BOERSMA, Paul \& HAMANN, Silke. Loanword adaptation as first-language phonological perception. In: CALABRESE, Andrea \& W. Leo Wetzels. Loan phonology 11-58. Amsterdam: Benjamins, 2009.

DAMULAKIS, Gean Nunes. Opacidade da inserção vocálica em contexto de fricativa coronal: o caso de empréstimos no PB. ReVEL, vol. 15, n. 28, 2017. [www.revel.inf.br]

JACOBS, Haike \& GUSSENHOVEN, Carlos. Loan Phonology: Perception, Salience, the Lexicon and OT. In: Dekkers, J.; Leeuw, F. van der; Weijer, J. van der (Eds). Optimality Theory, Phonology, Syntax and Acquisition. Oxford: Oxford University Press, 2000.

JURGEC, Peter. Morphology affects loanword phonology. In: HUANG, Hsin-Lun; POOLE, Ethan \& RYSLING, Amanda (Eds). Proceedings of NELS 43, v. 1. Amherst, MA: GLSA, 192-202, 2014.

HAMANN, Silke; COLOMBO, Ilaria E. A formal account of the interaction of orthography and perception: English intervocalic consonants borrowed into Italian. Natural Language \& Linguistic Theory, v. 35, n. 3, 2017.

HASPELMATH, M. \& TADMOR, U. Loanwords in the World's Languages: A Comparative Handbook. Berlin: De Gruyter Mouton. 2009.

HOUAISS, Antônio. Dicionário Houaiss da Lingua Portuguesa. Rio de Janeiro, Ed. Objetiva, 2001.

PEPERKAMP, Sharon. A Psycholinguistics Theory of Loanword Adaptations. Annual Meeting of the Berkeley Linguistics Society, v. 30, p. 341-352, 2004.

SILVERMAN, Daniel. Multiple scansion in loanword phonology: evidence from Cantonese. Phonology 9. Cambridge University Press, p. 289-328, 1992. 